\title{
Review of experiences: recurrent pregnancy loss with reproductive outcome in pregnant women
}

\author{
Urvi Gupta ${ }^{1}$, M. Alwani ${ }^{1 *}$, Susmit Kosta ${ }^{2}$
}

\begin{abstract}
${ }^{1}$ Department of Obstetrics and Gynecology, ${ }^{2}$ Central Research Lab, Sri Aurobindo Institute of Medical Sciences, Indore, Madhya Pradesh, India
\end{abstract}

Received: 03 November 2018

Accepted: 06 December 2018

\author{
*Correspondence: \\ Dr. M. Alwani, \\ E-mail: drmadhuri_2007@rediffmail.com
}

Copyright: () the author(s), publisher and licensee Medip Academy. This is an open-access article distributed under the terms of the Creative Commons Attribution Non-Commercial License, which permits unrestricted non-commercial use, distribution, and reproduction in any medium, provided the original work is properly cited.

\begin{abstract}
Background: Recurrent pregnancy loss (RPL) is an important reproductive health issue, affecting $2 \%-5 \%$ of couples. Research into why miscarriage happens is the only way we can save lives and prevent future loss. In this study we estimate the percentage of babies who survived beyond the neonatal period in a RPL clinic and to identify associated factors.

Methods: A retrospective cohort study including 128 women seen at a clinic for RPL in loss group between 2016 and 2018 and a control group including 180 pregnant women seen at a low-risk prenatal care unit. Reproductive success rate was defined as an alive-birth, independent of gestational age at birth and survival after the neonatal period. All the date was statically reviewed and analyzed.

Results: Out of 115 who conceived, $105(91.3 \%)$ had reproductive success rate. There were more full-term pregnancies in the control than in the loss group $(155 / 180 ; 89.6 \%$ versus $67 / 115 ; 58.3 \%$; $p<0.01)$. The prenatal visits number was satisfactory for $97(84.3 \%)$ women in the loss group and $112(62.2 \%)$ in the control $(\mathrm{p}<0.01)$. In this, the beginning of prenatal care was earlier ( $13.5 \pm 4$.3versus $18.3 \pm 6.1$ weeks). During pregnancy, the loss group women increased the weight more than those in the control group $(57.4 \%$ versus $47.8 \% \mathrm{p}=0.01)$. Although cervix cerclage was performed in $41 / 115(35.7 \%)$ women in the loss group, the pregnancy duration mean was smaller $(34.6 \pm 5.1$ weeks versus $38.2 \pm 2.5$ weeks; $\mathrm{p}<0.01$ ) than in the control group. Due to gestational complications, cesarean delivery predominated in the loss group $(71 / 115 ; 61.7 \%$ versus $69 / 180 ; 38.3 \%, \mathrm{p}<0.01)$.

Conclusions: A very good reproductive success rate can be attributed to greater availability of healthcare services to receive pregnant women, through prenatal visits scheduled or not, cervical cerclage performed on time and available hospital care for the mother and newborn.
\end{abstract}

Keywords: Outcome, Pregnant women, Recurrent pregnancy loss (RPL), Reproductive

\section{INTRODUCTION}

Recurrent pregnancy loss (RPL) was initially defined as the loss of three or more clinically recognized pregnancies spontaneously during early gestation. However, the modern definition refers to the RPL was defined by the European society of human reproduction and embryology (ESHRE) and the Royal college of obstetricians and Gynecologists (RCOG) as three consecutive pregnancy losses at less than 20 weeks of gestation. ${ }^{1,2}$ Regardless of these definitive criteria, many physicians commenced clinical examinations after just the second pregnancy loss, because they realized that little clinical insight was gained from investigation after a third loss. ${ }^{3}$ Thus, in 2008, the American society of reproductive medicine (ASRM) published an amended definition of RPL. ${ }^{4}$ The ASRM still insists that cases of two consecutive losses should be judged individually for 
need of further clinical evaluation and recommends a thorough investigation only after three losses. ${ }^{5}$ Approximately $15 \%$ of all clinically recognized pregnancies result in spontaneous loss and many pregnancies are lost before a woman realizes that she is pregnant. The reported possible etiology of RSM includes genetic factors, uterine anatomical defects, infection, endocrine, and immunological factors. Maternal age and the number of prior spontaneous miscarriages are also associated with recurrent miscarriages. ${ }^{6}$ The risk of subsequent miscarriage after the first two and three pregnancy losses is 30 and $33 \%$, respectively, in women without a history of live birth. ${ }^{7}$

As the diagnosis of RPL is based on self-reported losses which occurred in the past, it may not be accurate, although there is an element which is not considered in the definitions above but is very important for the patients the biochemical loss. ${ }^{8}$ Women in the general population do not have their $\beta \mathrm{hCG}$ routinely measured and, consequently, their biochemical loss rate is underestimated. In contrast, women with RPL often have closer biochemical monitoring, which is less likely to be missed. A study shows that 3,165 women undergoing IVF have significantly higher reported biochemical pregnancy losses compared with 954 women with RPL (18.4 versus $7.9 \%, \mathrm{p}<0.001) .{ }^{9}$ If the biochemical losses were to be considered true miscarriages, this would promote an increase in the rate in general population as high as $60 \%$. These women may suffer three biochemical pregnancy losses due to chance alone. From this, the authors 5 estimated that the incidence of RPL occurring by chance varies significantly with age, ranging from 0.13 to $13.3 \%$ for ages 20 to 24 and 40 to 44 , respectively. The proportion of women with unexplained RPL (approximately one of three) may have environmental risk factors or endogenous pathologies not detected by current routine investigations.

The inclusion criterion of patients with RPL is very important in the comparison and interpretation of results, because failed pregnancies can occur at several gestational ages, although they predominate in the firsttrimester, after late miscarriages, and very preterm. ${ }^{10,11}$ One study, including 325 women with unexplained RPL, of which 226 conceived, the success rate was $75 \%$, with successful outcome being regarded as survival beyond 24 weeks. ${ }^{12}$ Another study, showed a $25 \%$ rate of miscarriages in women less than 30 years, increasing to $52 \%$ in a group of women older than 40 years. ${ }^{13}$ After investigation, the women with unexplained recurrent first trimester mis-carriage had an excellent pregnancy outcome without pharmacological intervention when they were offered supportive care in the setting of a dedicated miscarriage clinic. They also concluded that increasing maternal age and number of previous miscarriages both had a negative effect on pregnancy outcome. To the contrary, a history of a live birth did not influence the outcome of the next pregnancy. In a tertiary academic centre, 51 couples with a structural chromosome rearrangement were followed prospectively, and after evaluation and treatment of concomitant factors there were 58 monitored pregnancies, with a live birth rate of $71 \% .^{14}$

In a population of women with RPL, losses are likely to occur again at gestational ages similar to those previously documented. ${ }^{11}$ These observations suggest the possibility of specific, but yet undiscovered, causes of loss that influence the viability of pregnancy at precise gestational ages. The chromosomal abnormalities are present in more than $90 \%$ of pre-embryonic-aborted tissues, compared with only 6 to $12 \%$ of losses after 20 weeks gestation. The women with mid-trimester pregnancy loss represent a heterogeneous group with widely varying presentations and origins.

Fetal loss may have more than one cause, and the presence of dual or even triple pathologies increases the risk of a further late-term miscarriage or preterm delivery. ${ }^{15}$ Mid-trimester pregnancy loss can be attributed to Anti-phospholipid Syndrome and anatomic cervical incompetence. These authors analysed 351 mid-trimester pregnancy loss women in a clinic in the UK, which showed $51 \%$ patients with unexplained causes and $33 \%$ with anti-phospholipid syndrome. ${ }^{15}$ These mid-trimester pregnancy loss cases are important because medical intervention can give them the possibility to progress beyond the early preterm period.

Cervical incompetence has been noticed as an important cause for mid-trimester pregnancy loss, in which surgical cure through the uterine cerclage has been a medical practice for several decades. ${ }^{16,17}$ In maintaining the fetus in the uterus, the results of uterine cerclage have been debated for years and its indication changed after the routine use of trans vaginal ultrasound for cervical evaluation. ${ }^{18-21}$

A study of 138 pregnant women treated with elective cerclage showed $54.3 \%$ of term deliveries and $9.0 \%$ preterm less than 25 weeks. ${ }^{21}$ The recovery of the cervical pessary the treatment with 17 alfa-hydro-oxyprogesterone corporate in addition to the advanced technology available to the neonatologists, have all contributed to a reduction in the rate of early preterm birth. $^{22-25}$ This has had a favourable impact on the survival and future well-being of new-born.

For women with unexplained recurrent miscarriage, with or without thrombophilia, the efficacy and safety of anticoagulant agents has been debated, and is very different from the proved efficacy in those with antiphospholipid syndrome. ${ }^{26-28}$

There is still a contingent of women with RPL in whom a thorough clinical and laboratory investigation reveals a normal health. For these women, supportive care in early pregnancy and prenatal consultations in the setting of a miscarriage clinic confer a significant beneficial effect on 
pregnancy outcome. The objective of this study was to estimate the percentage of babies who survived beyond the neonatal period in an RPL clinic and to identify associated factors with favourable results.

\section{METHODS}

This study was conducted with female patients aged between 18 and 45 years with a history of at least one recurrent pregnancy loss of $\geq 20$ weeks of gestation and willing to sign the patient authorization form were included in the study.

A retrospective cohort study consisting of interviews and medical-record reviews of 128 women who were seen at an RPL clinic in loss group and control group consisted of 180 pregnant women seen at a low-risk prenatal care between 2016 and 2018 at Department of Obstetrics and Gynecology at Sri Aurobindo Medical College and PG Institute, Indore, Madhya Pradesh, India.

From the 128 who were included, 115 had their gestation period followed in the clinic and 13 did not conceive. There was not known selection bias to include low risk care unit. The patients visiting the clinic for routine clinical visits were screened to obtain information on eligibility and availability of data.

The investigator discussed the study with eligible patients and recruited those willing to sign the patient authorization form. Each enrolled patient was identified by a unique patient identification number to maintain patient confidentiality. The information regarding patient demography, systolic and diastolic measurements, medical history, associated risk factors or conditions that may affect the outcome of pregnancy, menstrual, gynecological and obstetric history and observations of gynecological examination was recorded.

No follow-up visits or any interventions were undertaken in this study. The analyzed variables on reproductive outcome were live-birth at term, preterm, miscarriages, prevalence $(\%)$ of female patients with RSM (defined as C3 consecutive pregnancy losses of $\leq 20$ weeks of gestation each) among the enrolled patients. Secondary study outcome included comparison of age-specific miscarriages in patients with $<3$ and $\geq 3$ spontaneous miscarriages of $\leq 20$ weeks of gestation, probability of a subsequent miscarriage after the first miscarriage; and the association between RPL and known risk factor.

The body mass index (BMI) was estimated for all patients. This was done through the Quetelet's formula and blood pressure measurements and was repeated at each consultation until the ending of prenatal care. ${ }^{29}$

Pre-gestational overweightness was considered when the first BMI (or up to 16 weeks gestation) was above 25 $\mathrm{kg} / \mathrm{m}^{2}$. The first BMI was utilized to estimate the increase of the maternal weight during the pregnancy, from what the allowed weight was classified into 3 categories: under, appropriate and above allowed.

This corresponded to the underweight, normal weight, overweight and obesity. ${ }^{30}$ Pre-eclampsia was considered when the blood pressure (BP) during pregnancy was $\mathrm{sBP} \geq 140 \mathrm{mmHg}$ or $\mathrm{dBP} \geq 90 \mathrm{mmHg}$ after 20 weeks gestation, with new proteinuria. Pre-existing (chronic) hypertension was considered either when it was present, in pre-pregnancy or when detected in before 20 weeks gestation. ${ }^{31}$ The screening cut-point for gestational diabetes mellitus was the fasting glucose measurements of $\geq 85 \mathrm{mg} / \mathrm{dL}$, after the 20 th week of pregnancy. The diagnosis of gestational diabetes mellitus was defined as: 2 fasting glucose measurements $\geq 126 \mathrm{mg} / \mathrm{dL}$ or glucose tolerance test with glucose levels $>200 \mathrm{mg} / \mathrm{dL}$ or any fasting glucose $\geq 200 \mathrm{mg} / \mathrm{dL}$ or the presence of classic symptoms of diabetes. ${ }^{32}$

The uterine cervix cerclage described by McDonald was the treatment when the pregnant women had a history of mid-trimester pregnancy loss or when the trans vaginal cervical ultrasound revealed a shortened endocervical canal length. ${ }^{17}$

Through interviews with patients and investigation of reference medical records, information was obtained on the outcome of pregnancies, mainly to low-risk prenatal patients, who had deliveries in hospitals other than in the university teaching hospital.

\section{Exclusion criteria}

- The control group consisted of 180 pregnant women seen in a low-risk prenatal care unit. Those with obstetric risk were sent to specialized care, and those who did not agree to be interviewed were excluded from the control group.

\section{Statistical analysis}

All analyses were performed in SPSS Version 21.0. Descriptive statistics were calculated to means and standard deviations of continuous variables were compared using Student's t-test, and the proportions of nominal variables were compared by Pearson $\chi^{2}$ test. Statistical association was considered for $\mathrm{p}$-value $<0.05$.

\section{RESULTS}

Of the 115 women who had their future pregnancy followed at the RPL clinic, $105(91.3 \%)$ had reproductive success outcome rate. Among these women, 67 (63.8\%) had full-term live births and $36(34.2 \%)$ had late preterm babies.

From the 180 patients of control group, we were able to obtain information on 173 women, and 166 (95.95\%) had reproductive success, mainly with full-term live births (Table1). 
Table1: Subcategories of preterm birth base on week of gestational age.

\begin{tabular}{|c|c|c|c|}
\hline & $\begin{array}{l}\text { Women } \\
\text { with } \\
\text { losses } \\
(\mathbf{n}=\mathbf{1 1 5})\end{array}$ & $\begin{array}{l}\text { Women } \\
\text { without } \\
\text { losses } \\
(\mathbf{n}=\mathbf{1 7 3})\end{array}$ & $\begin{array}{l}\text { P- } \\
\text { value }\end{array}$ \\
\hline Miscarriage & $3(2.6 \%)$ & $2(1.2 \%)$ & \multirow{5}{*}{$<0.01$} \\
\hline $\begin{array}{l}\text { Extremely preterm } \\
(22<28 \text { weeks })\end{array}$ & $1(0.9 \%)$ & $5(2.8 \%)$ & \\
\hline $\begin{array}{l}\text { Very preterm }(28< \\
32 \text { weeks })\end{array}$ & $8(6.9 \%)$ & $2(1.2 \%)$ & \\
\hline $\begin{array}{l}\text { Moderate to late } \\
\text { preterm } \\
(32<37 \text { weeks })\end{array}$ & $\begin{array}{l}36 \\
(31.3 \%)\end{array}$ & $\begin{array}{l}9 \\
(5.2 \%)\end{array}$ & \\
\hline $\begin{array}{l}\text { Full term } \\
\text { (>37 weeks) }\end{array}$ & $\begin{array}{l}67 \\
(58.3 \%)\end{array}$ & $\begin{array}{l}155 \\
(89.6 \%)\end{array}$ & \\
\hline
\end{tabular}

The pregnant women in the loss group started the prenatal period with a higher BMI, and, even with a specialist support, they had a weight increased more than expected during the pregnancy, as can be seen in Table 2.

Table 2: Clinical data on pregnancy and delivery.

\begin{tabular}{|c|c|c|c|}
\hline & $\begin{array}{l}\text { Women } \\
\text { with } \\
\text { losses }\end{array}$ & $\begin{array}{l}\text { Women } \\
\text { without } \\
\text { losses }\end{array}$ & $\begin{array}{l}\mathrm{p} \text { - } \\
\text { value }\end{array}$ \\
\hline & $(n=115)$ & $(n=180)$ & \\
\hline \multicolumn{4}{|c|}{ Pre-pregnancy body mass index } \\
\hline Normal & $52(45.2 \%)$ & $142(78.9 \%)$ & $<0.01$ \\
\hline Overweight & $34(29.6 \%)$ & $20(11.1 \%)$ & $<0.01$ \\
\hline Obesity & $29(25.2 \%)$ & $18(10.0 \%)$ & $<0.01$ \\
\hline \multicolumn{4}{|c|}{ Appropriateness of pregnancy weight gain } \\
\hline Under & $15(13.0 \%)$ & $51(28.3 \%)$ & $<0.01$ \\
\hline Appropriate & $34(29.6 \%)$ & $43(23.9 \%)$ & 0.08 \\
\hline Above & $66(57.4 \%)$ & $86(47.8 \%)$ & $<0.01$ \\
\hline \multicolumn{4}{|l|}{ Cesarean } \\
\hline Delivery & $71(61.7 \%)$ & $69(38.3 \%)$ & $<0.01$ \\
\hline \multicolumn{4}{|l|}{ Pre-natal care } \\
\hline $\begin{array}{l}\text { First clinical visit } \\
\text { (weeks; } \mathrm{M} \pm \mathrm{SD} \text { ) }\end{array}$ & $13.5 \pm 4.3$ & $18.3 \pm 6.1$ & $<0.01$ \\
\hline $\begin{array}{l}\text { Last visit } \\
\text { (weeks; } \mathrm{M} \pm \mathrm{SD} \text { ) }\end{array}$ & $34.6 \pm 5.1$ & $38.2 \pm 2.5$ & $<0.01$ \\
\hline $\begin{array}{l}\text { Number and } \\
\text { percent of women } \\
\text { with five or more } \\
\text { visits }\end{array}$ & $97(84.3 \%)$ & $112(62.2 \%)$ & $<0.01$ \\
\hline \multicolumn{4}{|l|}{ Comorbidities } \\
\hline Hypertension & $35(30.4 \%)$ & $10(5.6 \%)$ & $<0.01$ \\
\hline $\begin{array}{l}\text { Gestational } \\
\text { diabetes mellitus }\end{array}$ & $7(6.1 \%)$ & $3(1.7 \%)$ & 0.05 \\
\hline
\end{tabular}

Cervix cerclage was performed in $41(35.7 \%)$ women in the loss group, and in 41 of them had term pregnancies. No surgery was needed in the control group. Eight women in the loss group had failed pregnancies due to miscarriages (weeks $14^{\text {th }}, 18^{\text {th }}$, and $21^{\text {st }}$ ). One woman had an extremely preterm live birth $\left(23^{\text {th }}\right.$ gestational week), who died soon after birth. One woman with SLE had preterm stillbirth $\left(30^{\text {th }}\right.$ gestational weeks). On the control group, there were three miscarriages and five extremely preterm (three neonatal deaths and two stillbirths).

\section{DISCUSSION}

RPL is an important reproductive health issue and several etiologies have been recognized over the years. A thorough follow-up with an important psychological support can help most couples achieve a successful live birth. In current study the reproductive success was 91.3\% considered satisfactory and very stimulating for the couples and all the involved healthcare professionals. The result mentions to all the subjects who had losses in several gestational ages, with predominance in the $1^{\text {st }}$ trimester, as we showed in prior study of this group. ${ }^{10}$ In ten of these cases, comorbidities that were not necessarily related to the RPL were identified. The majority of cases were healthy pregnant women, a result that does not concur with published studies showing half of cases of RPL having an unexplained cause. ${ }^{33}$ The group of 52 pregnant women who mainly had first trimester miscarriages had more reproductive success 50/52 (96.1\%,95\%CI 91.3-98.2). Other authors who analyzed reproductive outcomes in 226 women with unexplained recurrent first trimester miscarriages related a success rate of $75 \% .^{12}$ The same was described in women with mean age of 30 years, with significant decrease in those older than 40 years old. ${ }^{9}$ The high rate of success in this study can be related to the fact that the majority of the women had two or three miscarriages and the inclusion of biochemical losses. If only clinical pregnancy losses and not biochemical losses are considered as miscarriages, then recurrent miscarriage is less likely to be due to chance. The favorable outcome in women with unexplained recurrent first trimester miscarriage has been largely related in literature and, to explain it, two models are proposed: types I and II. ${ }^{15,17}$ type I is the RPL which occurs mainly by chance, in women who have no underlying pathology. There is a relatively good prognosis when compared with women of the same age, without pharmacological intervention, if supportive care alone is offered in the setting of a dedicated miscarriage clinic.

Five pregnant women in this study, out of 52 unexplained recurrent first trimester miscarriages, showed an endocervical canal length shortened by ultrasound and were treated with cerclage. Three, including one with bicornuate uteri, had a successful pregnancy. Two presented amniorrexe, amnionitis and had a miscarriage at twenty weeks. An ultrasound screening showed it to be effective in identifying the risk of preterm birth with evident decrease of costs. ${ }^{34}$ The women treated with curettages for prior miscarriages, even early miscarriages, can develop cervical incompetence, and these women can improve their odds of a successful pregnancy with the cerclage procedure, as it is related. In 52 subjects of this study, the previous losses were predominantly mid- 
trimester pregnancy losses. Of these 52 subjects, 31 were treated with cerclage, and in 21 the surgery promoted the prolongation of the pregnancy, enough to bring the fetus up to the category of late preterm, in which all survived the neonatal period. The support of the neonatology hospital unit, which limits the time for viability at 28 weeks, was fundamental to the gestational success, which was not only in the neonatal period, because there was no notice of death of these children until the time of the interviews. In two patients, the miscarriages occurred at the $13^{\text {th }}$ and $17^{\text {th }}$ weeks, and were probably not related to anatomic factor, which is passive of surgical healing.

Of the 115 subjects in this study, $41(35.7 \%)$ were treated with cerclage. In $67(58.3 \%)$ cases, the pregnancies were full term, and $36(31.3 \%)$ cases were late preterm, with a very favorable neonatal prognosis. A study which evaluated 138 pregnant women treated with cerclage by the McDonald method revealed a rate of $54.3 \%$ for full term pregnancies. ${ }^{17,21}$ The authors revealed the same pregnancy outcomes in women treated with elective versus ultrasound indicated cervical cerclage. In this study, the two indicated the ways used in addition to a large prescription of progesterone. The majority of pregnancies were full term, and even the preterm pregnancies exceeded the viability bound, which reached the authors and patients objective.

In the control group, even though the majority had been full term pregnancies, there were two still-born with 26 weeks and two at $25^{\text {th }}$ and $26^{\text {th }}$ weeks, who died after birth. It is quite notable that one of the factors that contribute to neonatal mortality is the number of prenatal consultations and the low-risk pregnant women had less than the loss group. ${ }^{35}$ This occurrence motivated the success and also presented significant difference in the gestational age at the beginning and ending of prenatal care, even when considering that thirty-nine of the cases in the loss group had their pregnancies interrupted early because of obstetrical complications. More women in the loss group started the prenatal care when they were overweight or obese and, despite the guidance of specialist, had more weight-gain during the pregnancy when compared with the low risk group.

These findings were associated with a greater risk of obstetrics complications and the same finding was observed among the women with RPL in this study, who progressed more proportionally with preeclampsia and gestational diabetes mellitus, which contributed to the early interruption of pregnancies in these women. ${ }^{36} \mathrm{~A}$ study that emphasized the effect of BMI on the outcome of pregnancy in women with recurrent unexplained miscarriages showed that maternal obesity significantly increased the risk of miscarriage. ${ }^{37}$ Another study to verify the association between BMI and future pregnancy in 696 women with recurrent unexplained miscarriage showed obesity as an independent factor of risk for a future miscarriage in addition to the maternal age and number of previous miscarriages. ${ }^{38}$ In this study, about one-third of the subjects were in a group classified as overweight/obese, although very few were obese. These authors and others recommend that all women with a history of RPL should have their BMI recorded at their first clinic visit. ${ }^{39}$

The favorable outcome, in women with recurrent unexplained miscarriages, who had more obstetrical complications, distinguishes the care the pregnant women received from the health group, even in a hospital for the training of medicine students. ${ }^{40}$ Prenatal consultations were scheduled, and patients were free to return to be seen by a doctor with a special interest in the RPL. It is also important that all staff members dealing with RPL couples are trained in the emotional aspects of pregnancy loss. This way, immediate support can be provided, and the couple will have direct access to specialized counselling and, when necessary, hospital care made available for mother and baby. ${ }^{39}$

The majority of women with two or three first-trimester miscarriages, the inclusion of biochemical losses and women in the first pregnancy in control group, although the majority progressed to full term live-birth, represented the limitations of this study, compromising the comparison of reproductive outcome and obstetrics complications. The objective of the study, however, was achieved as we demonstrated the reality at a clinic for RPL in a public hospital, and how it is possible to change a history of failure and frustration in gestational success through attentive prenatal care and interventions with average complexity to the mother and baby.

\section{CONCLUSION}

The majority of women with two or three first-trimester miscarriages, the inclusion of biochemical losses and women in the first pregnancy in control group, although the majority progressed to full term live-birth, represented the limitations of this study, compromising the comparison of reproductive outcome and obstetrics complications.

The objective of the study was to achieve as we demonstrated the reality at a clinic for recurrent pregnancy loss in a public hospital, and how it is possible to change a history of failure and frustration in gestational success through attentive prenatal care and interventions with average complexity to the mother and baby.

\section{ACKNOWLEDGMENTS}

Authors would like to thank all neonatal and obstetrician team at Department of Obstetrics and Gynecology, SAIMS, Indore for specialized counseling and providing data to the overweight/obese pregnant women followed at a clinic for recurrent pregnancy loss.

\section{Funding: No funding sources}


Conflict of interest: None declared

Ethical approval: The study was approved by the Institutional Ethics Committee

\section{REFERENCES}

1. Rai R, Regan L. Recurrent miscarriage. Lancet. 2006;368:601-11.

2. Jauniaux E, Farquharson RG, Christiansen OB, Exalto N. Evidencebased guidelines for the investigation and medical treatment of recurrent miscarriage. Human Reproduction.2006;21:2216-2.

3. Jaslow CR, Carney JL, Kutteh WH. Diagnostic factors identified in 1020 women with two versus three or more recurrent pregnancy losses. Fertility Sterility.2010;93:1234-43.

4. Definitions of infertility and recurrent pregnancy loss. Fertility and sterility.2008;90:60.

5. Definitions of infertility and recurrent pregnancy loss: a committee opinion. Fertility Sterility.2013;99:63

6. Li TC, Makris M, Tomsu M, Tuckerman E, Laird S. Recurrent miscarriage: aetiology, management and prognosis. Human Reproduction update. 2002;8(5):463-81.

7. Ford HB, Schust DJ. Recurrent pregnancy loss: etiology, diagnosis, and therapy. Rev Obstet Gynecol. 2009;2(2):76-83.

8. Kolte AM, van Oppenraaij RH, Quenby S, Farquharson RG, Stephenson M, Goddijn M, et al. Non-visualized pregnancy losses and prognostically important for unexplained recurrent miscarriage. Hum Reprod. 2014;29(5):931-7.

9. Saravelos $\mathrm{SH}, \mathrm{Li}$ TC. Unexplained recurrent miscarriage: how can we explain it? Hum Reprod. 2012;27(7):1882-6.

10. Costa OL, Santos EM, Netto EM. Epidemiological and obstetrics aspects in women with recurrent pregnancy losses at a public maternity in the Brazilian Northeast. Brazilian J Gynecol Obstetr. 2014;36(11):514-8.

11. Heuser C, Dalton J, Macpherson C, Branch DW, Porter TF, Silver RM. Idiopathic recurrent pregnancy loss recurs at similar gestational ages. Am J Obstet Gynecol. 2010;203(4):343.e1-5.

12. Brigham SA, Conlon C, Farquharson RG. A longitudinal study of pregnancy outcome following idiopathic recurrent miscarriage. Hum Reprod.1999; 14(11):2868-71.

13. Clifford K, Rai R, Regan L. Future pregnancy outcome in unexplained recurrent first trimester miscarriage. Hum Reprod. 1997;12(2):387-9.

14. Stephenson MD, Sierra S. Reproductive outcomes in recurrent pregnancy loss associated with a parental carrier of a structural chromosome rearrangement. Hum Reprod. 2006;21(4):1076-82.

15. McNamee KM, Dawood F, Farquharson RG. Midtrimester pregnancy loss. Obstet Gynecol North Am. 2014; 41(1):87-102.
16. Shirodkar VN. A new method of operative treatment for habitual abortions in the second trimester of pregnancy. Antiseptic. 1955;52:299-300.

17. McDonald IA. Suture of the cervix for inevitable miscarriage. J Obstet Gynaecol Br Emp.1957; 64(3):346-50.

18. Althuisius SM, Dekker GA, Hummel P, Bekedam DJ, van Geijn HP. Final results of the Cervical Incompetence Prevention Randomized Cerclage Trial (CIPRAT): therapeutic cerclage with bed rest versus bed rest alone. Am J Obstet Gynecol. 2001;185(5):1106-12.

19. Odibo AO, Berghella V, To MS, Rust AO, Althuisius SM, Nicolaides KH. Shirodkar versus McDonald cerclage for the prevention of preterm birth in women with a short cervical lenght. Am J Perinatol.2007;24(1):55-60.

20. Rust AO, Atlas RO, Jones KJ, Benhan BN, Balducci J. A randomized trial of cerclage versus no cerclage among patients with ultrasonographically detected second trimester preterm dilatation of the internal os. Am J Obstet Gynecol.2000;183(4):830-5.

21. Guzman ER, Forster JK, Vintzileos CV, Ananth CV, Walters C, Gipson K. Pregnancy outcomes in women treated with elective versus ultrasound-indicated cervical cerclage. Ultrasound Obstet Gynecol.1998; 12(5):323-7.

22. Goya M, Pratcorona L, Merced C, Rodó C, Valle L, Romero A, et al. Cervical pessary in pregnant women with a short cervix (PECEP): an open-label randomised controlled trial. Lancet.2012; 379(9828): 1790-7.

23. Hui SY, Chor CM, Lau TK, Lao TT, Leung TY. Cerclagepessary for preventing preterm birth in women with a singleton pregnancy and short cervix at 20 to 24 weeks: a randomized controlled trial. Am J Perinatol. 2013;30(4):283-8.

24. Rafael TJ, Mackeen AD, Berghella V. The effect of 17- $\alpha$-hydroxypr ogesteronecaproate on preterm birth in women with an ultrasound-indicated cerclage. Am J Perinatol.2011;28(5):389-94.

25. Alfirevic Z, Owen J, Carreras Moratonas E, Sharp AN, Szychowski JM, Goya M. Vaginal progesterone, cerclage or cervical pessary for preventing preterm birth in asymptomatic singleton pregnant women with a history of preterm birth and a sonographic short cervix. Ultrasound Obstet Gynecol. 2013;41(2):146-51.

26. Badawy AM, Khiary M, Sheriff LS, Hassan M, Ragab A, Abdelall I. Low-molecular weight heparin in patients with recurrent early miscarriages of unknown aetiology. J Obstet Gynecol.2008;28(3):280-4.

27. de Jong PG, Kaandorp S, Di Nisio M, Goddijn M, Middeldorp S. Aspirin and/or heparin for women with unexplained recurrent miscarriage with or without inherited thrombophilia. Cochrane Database Systematic Reviews. 2014(7). 
28. Kutteh WH, Hinote CD. Anti-phosphor lipid antibody syndrome. Obstet Gynecol Clin North Am. 2014;41(1):113-32.

29. Bhattacharya S, Campbell DM, Liston WA, Bhattacharya S. Effect of body mass index on pregnancy outcomes in nulliparous women delivering singleton babies. BMC Public Health. 2007;7:168.

30. Atalah Samur E, Castilho LC, Castro Santoro R, Aldea PA. Proposal of a new standard of nutritional evaluation in pregnant women. Rev Med Chile. 1997;125(12):1429-36.

31. Dadelszen P, Magee LA. Pre-eclampsia: an update. Curr Hypertens Rep. 2014;16(8):454.

32. Brazilian Federation of Gynecology and Obstetrics Associations.Handbook of guidance: high risk gestation. Rio de Janeiro: FEBRASGO; 2012.

33. Practice Committee of the American Society for Reproductive Medicine. Evaluation and treatment of recurrent pregnancy loss: a committee opinion. Fertil Steril. 2012; 98(5):1103-11.

34. Cahill AG, Odibo AO, Caughey AB, Stamilio DM, Hassan SS, Macones GA, et al. Universal cervical length screening and treatment with vaginal progesterone to prevent preterm birth: a decision and economic analysis. Am J Obstet Gynecol.2010; 202(6):548.e1-8.

35. Andrade LG, Amorim MM, Cunha AS, Leite SR, Vital SA. Factors associated with stillbirth in a school maternity in Pernambuco: a case control study. Brazilian J Gynecol Obstetr.2009;31(6):28592.

36. Gonçalves CV, Mendoza-Sassi RA, Cesar JA, Castro NB, Bortolomedi AP. [Body mass index and gestational weight gain as factors predicting complications and pregnancy outcome]. Rev Bras Ginecol Obstet. 2012;34(7):304-9.

37. Lo W, Rai R, Hameed A, Brailsford SR, Al-Ghamdi AA, Reagan L. The effect of body mass index on the outcome of pregnancy in women with recurrent miscarriage. J Family Community Med.2012; 19(3):167-71.

38. Metwally M, Saravelos SH, Ledger WL, Li TC. Body mass index and risk of miscarriage in women with recurrent miscarriage. Fertil Steril.2010; 94(1):290-5.

39. Van den Berg MM, Vissenberg R, Goddijn M. Recurrent miscarriage clinics. Obstetr Gynecol Clinics. 2014;41(1):145-5.

40. Shapira E, Ratzon R, Shohan-Vardi I, Serjienko R, Mazor M, Bashiri A. Primary vs. secondary recurrent pregnancy loss- epidemiological characteristics, etiology, and next pregnancy outcome. J Perinat Med. 2012; 40(4):389-96.

Cite this article as: Gupta U, Alwani M, Kosta S.

Review of experiences: recurrent pregnancy loss with reproductive outcome in pregnant women. Int J Reprod Contracept Obstet Gynecol 2019;8:1120-6. 